\title{
Treatment of Dissociative Symptoms and Depression as a Consequence of Mother's Neglect during Childhood, using EMDR: Two Case Studies
}

\author{
Usha Verma Srivastava \\ Assistant professor, Career Guidance and Counselling Cell, BHU, Varanasi \\ Corresponding author: Usha Verma Srivastava \\ Email - usha_verma1@yahoo.co.in
}

\begin{abstract}
The present study reports two cases where clients (age $19-23$ yrs) suffer from major depressive disorder along with dissociative symptoms. History revealed emotional unavailability, neglect, and physical and verbal abuse by mother. Clients were assessed on Dissociative experience scale (DES) and Beck Depression inventory (BDI). Psychotherapeutic intervention was provided. Clients responded well with Eye Movement Desensitization and Reprocessing (EMDR) and after almost one year of treatment, show improvement in their DES and BDI scores. They become assertive to cope with the situation at home and stable enough to carry out their day to day life. In both the above mentioned cases, mother's emotional abuse and emotional neglect during childhood produced the long term impact, thus generating a negative self schema and flawed perception of outer world which resulted in PTSD as well as dissociative symptoms and depression. Their shattered ego required a long preparation phase. EMDR helped them in healing and in enhancing their coping pattern.
\end{abstract}

Keywords: Dissociation, Major depressive disorder, EMDR, mother's neglect, perpetrator.

(Paper received $-30^{\text {th }}$ December 2017, Peer review completed $-6^{\text {th }}$ January 2018)

(Accepted $-12^{\text {th }}$ January 2018)

\section{INTRODUCTION}

Childhood maltreatment has devastating consequences. Mothers are the primary caregivers during childhood, and if the mother is the perpetrator, the risk to developing dissociative symptoms and depression increases many folds. However, not all forms of child maltreatment are physical in nature [1], and non-physical forms of maltreatment like emotional unavailability of the primary caregiver are equally important to consider as its impact on developing mind has dire consequences. There are many studies available, on the long term impact of physical and sexual abuse during childhood, on mental health but long term impact of emotional maltreatment on mental health is a less studied field [2-3].

Emotional maltreatment can be broadly defined as "a repeated pattern of caregiver behavior or extreme incident(s) that convey to children that they are flawed, unloved, unwanted, endangered, or of value only in meeting another's needs" [4]. Chamberland, Fallon, Black, Nico and Chabot considered that emotional maltreatment is a core component underlying all forms of child maltreatment that has equivalent, if not greater, developmental consequences than childhood experiences of physical and or sexual abuse [5].

Emotional maltreatment is a difficult construct to define and measure $[2,6]$ and many different acts can be considered emotionally abusive. Taillieu, Brownridge, Sareen and Afifi explained that term emotional 
maltreatment encompasses both acts of commission (i.e., emotional abuse) and acts of omission (i.e., emotional neglect) [7-8].

Attachment theory emphasizes the significance of secure attachment of a child to his primary caregiver. John Bowlby stated that a young child needs to develop a relationship with at least one primary caregiver for social and emotional development to occur normally. This pattern of attachment, developed in accordance with parental response directs their internal working model and hence guides the individual's feelings, thoughts and expectations in later relationships. When this attachment bond with caregiver is insecure due to emotional maltreatment it affects child's self perception, his personal security which can then manifests as mood, anxiety and/ or substance abuse disorder [9-10].

Childhood emotional maltreatment has been found to be associated with several psychological disorders like depression, anxiety, dissociative symptoms, post traumatic stress disorder, psychotic disorders, substance abuse, and axis II personality disorders. It is also associated with low self esteem and decreased quality of life [11-12].

Dissociation refers to disruptions of aspects of consciousness, identity, memory, and physical actions. Dissociation presents as separation/disconnection from immediate experience and occurs beyond conscious awareness and control. It also varies in type and intensity. Dissociation can range from healthy and benign to problematic and pathological and it often goes undetected as it manifests in subtle ways.

Depression is a serious medical condition that affects thoughts, feelings, and the ability to function in everyday life. Depression is a disorder of high prevalence and moderate to high severity and it can occur at any age. This article presents two case reports of girls with a history of childhood emotional as well as physical maltreatment by mother and major depressive episode with dissociative symptoms.

\section{CASE 1}

Client $\mathrm{P}$ is 23 years old educated, unmarried female belonging to middle class socioeconomic status. She came to the clinic with the complaint of persistent feeling of sadness, tiredness, lack of sleep, anxiety, anger outbursts, lack of concentration and memory problems. Her DES [13] score was 33 and her score on Beck Depression inventory was 41 .

History revealed that she was the only child and mother, has no apparent physical illness is but almost bedridden and father is very busy in his profession. She recalled when she was 8 years old, the death of her grandmother had a great impact on her and she never felt happy since then. Mother was always emotionally unavailable, sometimes stating that why God was so cruel that he gave her only one child that was a girl. Relationship between mother and father was overtly unpleasant. She said that mother was hard to please and kept on blaming father and his family for her misery. Her earlier memories were very traumatic. Her mother used to tie her to the chair to finish her household chores, because she was naughty. After her grandmother's death, she cried a lot but no one ever came to sooth her. She has no friends. She trusts people easily and make friends but somehow they end up fighting and breaking up.

She also had a boyfriend when she came for therapy and she was physically involved with him. She felt that he was not giving her sufficient time and she had an overall bad feeling about the relationship. She wanted him to come for counselling too, but he refused. They broke up after six months, adding to her depressive symptoms.

She has no memory of her life from the age of 13 to 16 . When asked about that period of her life she become agitated and could not remember. Similarly, many other memory gaps were there in her life history. Her positive memories were with her father who always took her to his friends and relatives. He feels proud of her and never put restrains on her. She can do whatever she wants, go out with her friends and stay late. She had no memory of her grandmother, just that she loved her very much.

She is in therapy since, one year. It took almost six months for resource building and preparing her for EMDR. She is still living with her parents but, both the parents are emotionally unavailable and she feels trapped. Father never restrains her but she thinks it is because he is not concerned and feels free when she is out. Her positive resource was her class teacher (when she was in class sixth), who was very caring and motivated her towards music. She is a good singer and pursuing Prabhakar degree in vocal music. Music is 
her refuge. Therapist motivated her to take part in singing activities, competitions and it improved her self esteem and helped her to become emotionally stable.

EMDR processing were never smooth, there were many episodes of abreactions. The main goal of therapy, initially, was to improve coping strategies of the client and to improve interpersonal relationships. Several episodes of fighting with friends were target for EMDR processing and she realized that she became demanding, emotionally dependent and suspicious in friendship and developed insight that it is because of her insecurity which is due to her negative relationship with her parents. Her dissociative symptoms were the result of her inability to face the traumatic memories. She was able to process her traumatic memories with her mother. EMDR helped her in accepting her parents with their faults. She was unable to forgive her mother but realized that she was not mentally healthy. She talked to a Psychiatrist about her mother's condition and she is hopeful if she could take her to psychiatrist, some medication might help. Though her mother is not accepting her request but she thinks she will manage it someday. She is also able to understand her father's struggle to raise a child single handed and now she spends time with him, talking to him and sometimes going out with him. She is working full time in a corporate firm. Managing her finances, coping with the loss of her love (her boyfriend) though bouts of depression were still present.

\section{CASE 2}

"S" is 20 years old unmarried educated female belonging to upper middle class socioeconomic status. Her presenting complaints were lack of concentration during studies, crying spells, and disinterest in everyday life, anger outbursts and, tiredness. She is pursuing her B.Sc and failed in two papers. Her DES score was 30 and her score on Beck Depression inventory was 43.

She was the only child and her father was suffering from Bipolar disorder. Mother is very aggressive, verbally and physically abusive and never misses any opportunity to humiliate her.There are several memories when she humiliated her in public places, in front of strangers stating that she is characterless and does all things to attract boys. She remembers her mother telling her "jis din se tum paida hui , mera durbhagya shuru ho gaya" (my bad luck started the day you were born). "tum meri sautan ho "(you are my husband's mistress).

Her father is also very aggressive and physically abuses her mother. She has seen lots of domestic violence at home. Her maternal aunt and her married cousin sister are also beaten up by their husbands. She has no support at home because if she talks to her cousin brothers, who love and support her, her mother creates scene stating that she is sexually involved with them. She has only one friend who belongs to lower caste, and her mother does not allow her to enter home insulting her friend many times for spoiling her daughter. "S" recalled that once her mother starts abusing her, she does not stop until she is completely exhausted. "S" tried to ran away and lock her room from inside but her mother kept on banging the door till she opened it. Also, she had tried to commit suicide by swallowing her father's medicines and slept for two days.

She cannot study or get involved with friends because she keeps on remembering these incidents, reliving it every time. She tried to get admission in hostel but her mother didn't allow saying that her father was only in control when she is at home. Resource building was difficult with her because she has no positive recourse and no positive memory. She has only one friend who is also struggling with her adverse life situations but fighting and surviving. It motivates her. Several EMDR sessions, targeting her memories of witnessing domestic violence, her mother's physical and verbal abuse have helped her in realizing the mental problems of her parents. Her dissociative symptoms arise because she was always engrossed in her traumatic memories and the helplessness of being trapped in that situation made her inattentive to her surroundings. Grounding exercises and EMDR processing improved her attention and orientation. She also realized that her way out of the situation is only her studies and getting a job. She cannot retaliate her mother's abuse but, now instead of breaking down into tears, she waits till her mother stops screaming and then gets back to her studies. Her negative cognition "I am unlucky" is still there but SUD is 2. EMDR protocol for ongoing traumatic stress [14] was used and it helped her in stabilizing. Her score of BDI after 32 sessions was 23 . And she managed to appear for her semester exams. 


\section{DISCUSSION}

A wide range of psychological problems and disorders are found to be associated with childhood maltreatment. Most common are major depression, low self esteem, poor quality of life, dysthemia, social phobia, mood and anxiety disorders, substance abuse, schizoid, schizotypal disorders, borderline and avoidant personality disorders, PTSD along with dissociative symptoms.

Ainsworth developed a theory of attachment patterns in infants as Secure attachment, Avoidant attachment, Anxious attachment and Disorganized attachment. Secure attachment results into secure interpersonal relationships in later life whereas other insecure attachments lead to adjustment problems, insecure interpersonal relationships, social and behavioral problems, and interferes with intellectual development and formation of social identity. According to Bowlby's attachment theory when the child is unable to form secure bond with the primary caregiver, it will lead to development of defective self schema as well as his/her perception of the outer world. The world becomes a cruel demanding and terrible place and is not worth living. Interpersonal relationships become insecure, demanding and full of paranoid suspicions.

Adults with childhood emotional neglect and abuse are unable to manage secure interpersonal relationships and need constant attention, reassurance and are unable to understand while someone will love them when they are so flawed. Childhood emotional abuse includes direct parental actions like threats, belittling, degradation and hostility which produces fear, threat to physical safety, damages self esteem and self acceptance. It openly gives the child's negative belief "I am worthless/ unwanted/ unlucky". Emotional neglect where caregiver denies emotional responsiveness to the child produces feeling of rejection and his faulty self schema attributes its responsibility on his own self instigating a chain of negative beliefs.

Studies suggest that parental rejection and low parental warmth and responsiveness are associated with externalizing problem behaviours among children and adolescents, e.g. criminality, aggression, impulsivity etc. [15-18] and it is possible that it manifests as externalizing problem throughout the lifespan.

In both the above mentioned cases, mother's emotional abuse and emotional neglect during childhood produced the long term impact, thus generating a negative self schema and flawed perception of outer world which resulted in PTSD as well as dissociative symptoms and depression. Their shattered ego required a long preparation phase. EMDR helped them in healing and in enhancing their coping pattern.

\section{REFERENCES}

1. Miller-Perrin CL, Perrin RD, Kocur JL. Parental physical and psychological aggression: Psychological symptoms in young adults. Child Abuse Negl 2009;33(1):1-11.

2. Ackner S, Skeate A, Patterson P, Neal A. Emotional abuse and psychosis: a recent review of the literature. J Aggr Maltreat Trauma 2013;22(9):1032-49.

3. Bifulco A, Moran PM, Baines R, Bunn A, Stanford K. Exploring psychological abuse in childhood: II. Association with other abuse and adult clinical depression. Bull Menninger Clin 2002;66(3):241-58.

4. Psychosocial evaluation of suspected psychological maltreatment in children and practice guidelines. American Professional Society on the Abuse of Children.. Chicago, IL: American Professional Society on the Abuse of Children ; 1995.

5. Chamberland C, Fallon B, Black T, Trocmé N, Chabot M. Correlates of substantiated emotional maltreatment in the second canadian incidence study. J Fam Violence 2012;27(3):201-13.

6. Baker AJ. Adult recall of childhood psychological maltreatment: Definitional strategies and challenges. Children Youth Serv Rev 2009;31(7):703-14.

7. Taillieu TL, Brownridge DA. Aggressive parental discipline experienced in childhood and internalizing problems in early adulthood. J Fam Violence 2013;28(5):445-58.

8. Taillieu TL, Brownridge DA, Sareen J, Afifi TO. Childhood emotional maltreatment and mental disorders: results from a nationally representative adult sample from the United States. Child Abuse Negl 2016;59:1-2.

9. Ainsworth MS. Infant-mother attachment. Amer Psychol 1979;34(10):932-50.

10. Kairys SW, Johnson CF, Committee on Child Abuse and Neglect. The psychological maltreatment of children-technical report. Pediatrics 2002;109(4):e68-80. 
11. Ferguson KS, Dacey CM. Anxiety, depression, and dissociation in women health care providers reporting a history of childhood psychological abuse. Child Abuse Negl 1997;21(10):941-52.

12. Hamilton JL, Shapero BG, Stange JP, Hamlat EJ, Abramson LY, Alloy LB. Emotional maltreatment, peer victimization, and depressive versus anxiety symptoms during adolescence: Hopelessness as a mediator. $\mathrm{J}$ Clin Child Adolesc Psychol 2013;42(3):332-47.

13. Bernstein E, Putnam FW, Ross CA, Torem M, Coons P, Dill DL, Loewenstein RJ, Braun BG. Validity of the Dissociative Experiences Scale in screening for multiple personality disorder: A multicenter study. Am J Psychiatry 1993;150:1030-6.

14. Luber M. Implementing EMDR early mental health interventions for man-made and natural disasters: Models, scripted protocols and summary sheets. Springer Publishing Company; 2013.

15. Muris P, Meesters C, van den Berg S. Internalizing and externalizing problems as correlates of self-reported attachment style and perceived parental rearing in normal adolescents. J Child Fam Stud 2003;12(2):171-83.

16. Roelofs J, Meesters C, ter Huurne M, Bamelis L, Muris P. On the links between attachment style, parental rearing behaviors, and internalizing and externalizing problems in non-clinical children. J Child Fam Stud 2006;15(3):319-25.

17. White R, Renk K. Externalizing behavior problems during adolescence: An ecological perspective. J Child Fam Stud 2012;21(1):158-71.

18. Vachon DD, Krueger RF, Rogosch FA, Cicchetti D. Assessment of the harmful psychiatric and behavioral effects of different forms of child maltreatment. JAMA Psychiatry 2015;72(11):1135-42.

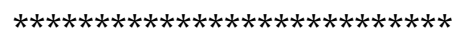

$$
\begin{gathered}
\text { Acknowledgements - Nil } \\
\text { Conflict of Interest - Nil } \\
\text { Funding - Nil }
\end{gathered}
$$

